\title{
MODELING THE ELECTRON TEMPERATURE DISTRIBUTION IN F2 REGION OF HIGH-LATITUDE IONOSPHERE FOR WINTER SOLSTICE CONDITIONS
}

\author{
I.A. Golikov' ${ }^{1}$ A.Yu. Gololobov ${ }^{2}$, V.I. Popov ${ }^{2}$ \\ ${ }^{1}$ Yu.G. Shafer Institute of Cosmophysical Research and Aeronomy, Yakutsk, Russia,gia2008@mail.ru \\ ${ }^{2}$ M.K. Ammosov North-Eastern Federal University, Yakutsk, Russia, golart87.gmail.com,volts@mail.ru
}

Using the three-dimensional model of the high-latitude ionosphere in Euler variables, which takes into account the mismatch between geographic and geomagnetic poles, we study the behavior of the electron temperature $T_{e}$ in the F2 region as a function of universal time. We present results of the numerical modeling of spatial-temporal distribution of electron temperature in the F2 region for winter solstice, minimum solar activity, and moderate geomagnetic activity. The electron temperature distribution in the F2 region of the high-latitude ionosphere in winter is shown to be characterized by a $T_{e}$ increase in dawn and dusk sectors. Further, the mismatch between the poles leads to regular longitudinal features in $T_{e}$ distribution during Earth's daily rotation. Thus, at 05 UT, when the Eastern Hemisphere is illuminated, the elevated $T_{e}$ zone is formed only in the dawn sector, and at 17 UT, when the Western Hemisphere is illuminated such zones are observed in both the sectors. We discuss reasons for the formation of the regions with elevated electron temperature depending on the universal time. Results of numerical experiments are compared with similar results obtained with other models.

Keywords High-latitude ionosphere $\cdot$ F2 region $\cdot$ Three-dimensional model $\cdot$ Rate of heating and cooling of electrons and ions - Electron and ion temperatures - Elevated electron temperature regions · Longitudinal features

\section{INTRODUCTION}

Mathematical modeling of the high-latitude ionosphere involves the numerical solution of hydrodynamic equations with due regard to the mismatch between geographic and geomagnetic poles. This is due to the fact that the large-scale structure of the high-latitude ionosphere is controlled by universal time (UT-control). Moreover, the mismatch should also affect the thermal regime of the high-latitude ionosphere. Therefore, when calculating spatial-temporal distribution of temperature of charged particles, a need arises to make allowance for the UT-control. The numerical simulation of thermal regime of the high-latitude ionosphere, which is based on the Lagrange approach, has been described in a number of papers [Schunk et al., 1986.; Klimenko et al., 1991; Mingalev et al., 2002], which analyze, in particular, causes for the formation of "hot spots" ( $T_{\mathrm{e}} \geq 5000 \mathrm{~K}$ ) [Koffman, 1984]. 
In this paper, we study the mismatch between the geographic and geomagnetic poles in the distribution of electron temperature in the F2 region of the high-latitude ionosphere in winter, using the Euler approach. This study relies on a three-dimensional model of the high-latitude ionosphere in Euler variables, which accounts for the thermal regime of the ionosphere. We make allowance for the mismatch between the geographic and geomagnetic poles, which produces the longitudinal effect in electron density distribution [Kolesnik et al., 1983]. We report the results of calculations of the spatial-temporal distribution of electron temperature in the F2 region for 05 and 17 UT when the Eastern and Western hemispheres are on the illuminated side. The calculations are made for winter solstice conditions, minimum solar activity, and moderate geomagnetic activity.

\section{MODEL OF THE HIGH-LATITUDE IONOSPHERE}

The model of the high-latitude ionosphere enables us to describe ionospheric plasma at a height range $120 \div 500 \mathrm{~km}$. It has the following set of parameters: densities of electrons $n_{\mathrm{e}}$, ions $n\left(\mathrm{O}^{+}\right)$, and basic neutral particles $n(\mathrm{O}), n\left(\mathrm{O}_{2}\right), n\left(\mathrm{~N}_{2}\right)$, as well as temperatures of electrons $T_{\mathrm{e}}$, ions $T_{\mathrm{i}}$, and neutral particles $T_{\mathrm{n}}$. In the height range considered, we can take the condition of plasma quasi-neutrality $n\left(\mathrm{O}^{+}\right)=n_{\mathrm{e}}$. We use a spherical geographic coordinate system: $r$ is a radius, $\theta$ is a colatitude, $\varphi$ is a longitude. The model equations are written in the form presented in [Kolesnik et al., 1993].

To determine the $\mathrm{O}^{+}$ion density, we use the continuity equation for $\mathrm{O}^{+}$:

$$
\frac{\partial n\left(\mathrm{O}^{+}\right)}{\partial t}=q\left(\mathrm{O}^{+}\right)-l\left(\mathrm{O}^{+}\right)-\frac{\partial}{\partial r}\left[n\left(\mathrm{O}^{+}\right) u_{\mathrm{i} r}\right]-\frac{1}{R_{\mathrm{E}} \sin \theta}\left\{\frac{\partial}{\partial \theta}\left[n\left(\mathrm{O}^{+}\right) u_{\mathrm{i} \theta} \sin \theta\right]+\frac{\partial}{\partial \varphi}\left[n\left(\mathrm{O}^{+}\right) u_{\mathrm{i} \varphi}\right]\right\},
$$

where $q\left(\mathrm{O}^{+}\right)$and $l\left(\mathrm{O}^{+}\right)$are rates of local formation and losses of $\mathrm{O}^{+}, \mathrm{cm}^{-3} \cdot \mathrm{s}^{-1} ; u_{\mathrm{i}}, u_{\mathrm{i} \theta}$, and $u_{\mathrm{i} \varphi}$ are components of the velocity vector of $\mathrm{O}^{+}, \mathrm{cm} \cdot \mathrm{s}^{-1} ; R_{\mathrm{E}}$ is the Earth radius.

Electron temperature distribution in the high-latitude ionosphere is calculated from the thermal conductivity equation for electrons:

$$
\begin{aligned}
& \frac{\partial T_{\mathrm{e}}}{\partial t}+u_{\mathrm{er}} \frac{\partial T_{\mathrm{e}}}{\partial r}+\frac{u_{\mathrm{e} \theta}}{R_{\mathrm{E}}} \frac{\partial T_{\mathrm{e}}}{\partial \theta}+\frac{u_{\mathrm{e} \varphi}}{R_{\mathrm{E}} \sin \theta} \frac{\partial T_{\mathrm{e}}}{\partial \varphi}=-\frac{2}{3} T_{\mathrm{e}}\left[\frac{\partial u_{\mathrm{er}}}{\partial r}+\frac{1}{R_{\mathrm{E}} \sin \theta} \frac{\partial}{\partial \theta}\left(u_{\mathrm{e} \theta} \sin \theta\right)+\frac{1}{R_{\mathrm{E}} \sin \theta} \frac{\partial u_{\mathrm{e} \varphi}}{\partial \varphi}\right]+ \\
& +\frac{2}{3 k n_{\mathrm{e}}}\left[\frac{H_{r}^{2}}{H^{2}} \frac{\partial}{\partial r}\left(\lambda_{\mathrm{e}} \frac{\partial T_{\mathrm{e}}}{\partial r}\right)+\frac{\lambda_{\mathrm{e}}}{R_{\mathrm{E}} \sin \theta} \frac{\partial}{\partial \theta}\left(\frac{H_{\theta} H_{r}}{H^{2}} \sin \theta\right) \frac{\partial T_{\mathrm{e}}}{\partial r}\right]+\frac{2}{3 k n_{\mathrm{e}}}\left(Q_{\mathrm{e} \lambda}+Q_{\mathrm{ep}}-L_{\mathrm{en}}-L_{\mathrm{ei}}\right),
\end{aligned}
$$

where $u_{\mathrm{e}}, u_{\mathrm{e} \theta}$, and $u_{\mathrm{e} \varphi}$ are components of electron velocity vector, $\mathrm{cm}^{\mathrm{s}} \cdot \mathrm{s}^{-1} ; \lambda_{\mathrm{e}}$ is the heat transfer coefficient of electrons; $Q_{\mathrm{e} \lambda}$ is the rate of local photoelectron heating of electrons, $\mathrm{erg} \mathrm{cm}^{-3} \cdot \mathrm{s}^{-1} ; Q_{\mathrm{ep}}$ is the rate of charged-particle heating of electrons, $\mathrm{erg} \mathrm{cm}^{-3} \cdot \mathrm{s}^{-1} ; L_{\mathrm{en}}$ and $L_{\mathrm{ei}}$ are rates of local heating or cooling of electrons due to elastic and inelastic collisions with neutral particles and ions respectively, $\mathrm{erg} \mathrm{cm}^{-3} \cdot \mathrm{s}^{-1}$.

The ion temperature is found from the thermal conductivity equation for ions: 


$$
\begin{aligned}
& \frac{\partial T_{\mathrm{i}}}{\partial t}+u_{\mathrm{i} r} \frac{\partial T_{\mathrm{i}}}{\partial r}+\frac{u_{\mathrm{i} \theta}}{R_{\mathrm{E}}} \frac{\partial T_{\mathrm{i}}}{\partial \theta}+\frac{u_{\mathrm{i} \varphi}}{R_{\mathrm{E}} \sin \theta} \frac{\partial T_{\mathrm{i}}}{\partial \varphi}=-\frac{2}{3} T_{\mathrm{i}}\left[\frac{\partial u_{\mathrm{i} r}}{\partial r}+\frac{1}{R_{\mathrm{E}} \sin \theta} \frac{\partial}{\partial \theta}\left(u_{\mathrm{i} \theta} \sin \theta\right)+\frac{1}{R_{\mathrm{E}} \sin \theta} \frac{\partial u_{\mathrm{i} \varphi}}{\partial \varphi}\right]+ \\
& +\frac{2}{3 k n_{\mathrm{i}}}\left[\frac{H_{r}^{2}}{H^{2}} \frac{\partial}{\partial r}\left(\lambda_{\mathrm{i}} \frac{\partial T_{\mathrm{i}}}{\partial r}\right)+\frac{\lambda_{\mathrm{i}}}{R_{\mathrm{E}} \sin \theta} \frac{\partial}{\partial \theta}\left(\frac{H_{\theta} H_{r}}{H^{2}} \sin \theta\right) \frac{\partial T_{\mathrm{i}}}{\partial r}\right]+\frac{2}{3 k n_{\mathrm{i}}}\left(Q_{\mathrm{ie}}-L_{\mathrm{in}}+Q_{\mathrm{id}}\right),
\end{aligned}
$$

where $\lambda_{\mathrm{i}}$ is the heat transfer coefficient of ions; $Q_{\mathrm{ie}}, L_{\text {in }}$ are rates of local heating or cooling of ions $\mathrm{O}^{+}$due to interaction with electrons and neutral particles, erg $\mathrm{cm}^{-3} \cdot \mathrm{s}^{-1} ; Q_{\text {id }}$ is the rate of $\mathrm{O}^{+}$heating by electric fields and thermospheric winds respectively, $\mathrm{erg} \mathrm{cm}^{-3} \cdot \mathrm{s}^{-1}$.

The equations for the components of $\mathrm{O}^{+}$velocity vector are defined as

$$
\begin{aligned}
& u_{\mathrm{i} r}=-D_{\mathrm{a}}\left\{\left[\frac{1}{n\left(\mathrm{O}^{+}\right)} \frac{\partial n\left(\mathrm{O}^{+}\right)}{\partial r}+\frac{1}{T_{\mathrm{p}}} \frac{\partial T_{\mathrm{p}}}{\partial r}+\frac{1}{H_{\mathrm{p}}}\right] \sin ^{2} I+\frac{1}{R_{\mathrm{E}}}\left[\frac{1}{n\left(\mathrm{O}^{+}\right)} \frac{\partial n\left(\mathrm{O}^{+}\right)}{\partial \theta}+\frac{1}{T_{\mathrm{i}}} \frac{\partial T_{\mathrm{i}}}{\partial r}\right] \cos I \sin I\right\}+ \\
& +\frac{c E_{\varphi}}{H} \cos I+u_{\mathrm{n} \theta} \sin I \cos I ; \\
& u_{\mathrm{i} \theta}=-D_{\mathrm{a}}\left\{\left[\frac{1}{n\left(\mathrm{O}^{+}\right)} \frac{\partial n\left(\mathrm{O}^{+}\right)}{\partial r}+\frac{1}{T_{\mathrm{p}}} \frac{\partial T_{\mathrm{p}}}{\partial r}+\frac{1}{H_{\mathrm{p}}}\right] \sin I \cos I+\frac{1}{R_{\mathrm{E}}}\left[\frac{1}{n\left(\mathrm{O}^{+}\right)} \frac{\partial n\left(\mathrm{O}^{+}\right)}{\partial \theta}+\frac{1}{T_{\mathrm{i}}} \frac{\partial T_{\mathrm{i}}}{\partial r}\right] \cos ^{2} I\right\}- \\
& -\frac{c E_{\varphi}}{H} \sin I+u_{\mathrm{n} \theta} \cos ^{2} I ; \\
& u_{\mathrm{i} \varphi}=\frac{c E_{\varphi}}{H} \operatorname{cosec} I,
\end{aligned}
$$

where $T_{\mathrm{p}}=T_{\mathrm{e}}+T_{\mathrm{i}} ; H_{\mathrm{p}}=k T_{\mathrm{i}} /\left(m\left(\mathrm{O}^{+}\right) g\right) ; k$ is the Boltzmann constant, erg $\cdot \mathrm{K}^{-1} ; g$ is the gravitational acceleration, $\mathrm{cm} \cdot \mathrm{s}^{-2} ; E_{\theta}$ and $E_{\varphi}$ are the meridional and zonal electric field components respectively, $\mathrm{V} \cdot \mathrm{cm}^{-1} ; H$ is the geomagnetic field strength, Oe; $D_{\mathrm{a}}$ is the ambipolar diffusion coefficient, $\mathrm{cm}^{2} \cdot \mathrm{s}^{-1} ; I$ is the geomagnetic inclination, deg; $u_{\mathrm{n} \theta}$ is the meridional component of neutral gas velocity, $\mathrm{cm} \cdot \mathrm{s}^{-1}$. When deriving (4), we drop the vertical electric field component $E_{r}$ as in [Stubbe, 1970]. To fulfill the quasi-neutrality condition, we put electron and ion velocities equal to $\left(\vec{u}_{\mathrm{e}}=\vec{u}_{\mathrm{i}}\right)$. We ignore the zonal thermospheric wind velocity component in this article because it is insignificant (directed across geomagnetic field lines) as compared to the meridional one.

We focus on the electron temperature and therefore use expressions for rates of heating and cooling of electron gas at heights of the F2 region. In the illuminated part of the high-latitude ionosphere, the main source of thermal electron heating is photoelectrons $Q_{\mathrm{e} \lambda}$ formed during photoionization, whereas in the auroral oval it is secondary electrons formed during corpuscular ionization $Q_{\mathrm{ep}}$. Respective heating rates are specified according to [Krinberg et al., 1984]:

$$
\begin{aligned}
& Q_{\mathrm{e \lambda}}=\varepsilon q_{\mathrm{ph}}, \\
& Q_{\mathrm{ep}}=\varepsilon q_{\text {corp }},
\end{aligned}
$$

where $q_{\mathrm{ph}}$ is the rate of ion formation due to shortwave solar radiation; $q_{\mathrm{corp}}$ is the corpuscular ionization rate; 


$$
\varepsilon=0.16\left(9+\lg \frac{n_{\mathrm{e}}}{\sum N_{\mathrm{n}}}\right)^{2} 1.602 \cdot 10^{-12}, \text { erg. }
$$

Thus, it follows that the regions of photoionization and photoelectron heating coincide. The rate of electron gas cooling due to elastic collisions with $\mathrm{O}^{+}$has the form [Banks et al., 1973]

$$
L_{\mathrm{ei}}=7.7 \cdot 10^{-6} n_{\mathrm{e}} T_{\mathrm{e}}^{-3 / 2}\left(T_{\mathrm{e}}-T_{\mathrm{i}}\right) \times \frac{n\left(\mathrm{O}^{+}\right)}{M\left(\mathrm{O}^{+}\right)} 1.602 \cdot 10^{-12}, \mathrm{erg} \cdot \mathrm{cm}^{-3} \cdot \mathrm{s}^{-1},
$$

where $M\left(\mathrm{O}^{+}\right)$is the ionic mass $\mathrm{O}^{+}$. Cooling rates of the electron gas when interacting with neutral particles are set in accordance with [Schunk et al., 1978]. Temperature and density of neutral components are calculated by the thermospheric model NRLEMSIS-00 [Picone et al., 2002]. The electric field of magnetospheric convection is specified by Heppner's model "A" [Heppner, 1977]. Corpuscular ionization is calculated using the Auroral Precipitation Model (APM) [Vorobjev et al., 2013], which defines energies and energy fluxes of precipitating electrons in the diffusion auroral zone, structural precipitation zone, and soft diffusion precipitation zone, as well as the function of ion formation by precipitating particles [Fang et al., 2008]. Wave ionization rates at wide solar zenith angles $\left(\chi^{>} 75^{\circ}\right)$ are specified according to [Chapman, 1931].

\section{ALGORITHM FOR SOLVING THE SYSTEM OF MODELING EQUATIONS}

To solve the system of modeling equations, we introduce a three-dimensional grid with nodes $r_{k}, \theta_{l}$, and $\varphi_{j}$ in height, colatitude and longitude respectively, which covers the entire solution domain $\left(120 \mathrm{~km} \leq h \leq 500 \mathrm{~km} ; 0 \leq \theta \leq 50^{\circ} ; 0 \leq \varphi \leq 2 \pi\right)$ so that

$$
r_{k+1}=r_{0}+k \Delta r ; \theta_{l}=l \Delta \theta ; \varphi_{j}=j \Delta \varphi,
$$

where $h=r_{0}-R_{\mathrm{E}} ; r_{0}=R_{\mathrm{E}}+120 \mathrm{~km} ; \Delta r, \Delta \theta, \Delta \varphi$ are distances between the nodes (steps) in coordinates $r$, $\theta, \varphi$ respectively; $k, l, j$ are integers that define the position of the nodes.

In the numerical solution of electron thermal conductivity equation (2), we set the following boundary conditions: at the lower boundary $(120 \mathrm{~km})$, high density of neutral gas provides thermal equilibrium of charged and neutral particles, therefore we can take the condition $T_{\mathrm{e}}=T_{\mathrm{i}}=T_{\mathrm{n}}$; at the upper boundary $(500 \mathrm{~km})$, we specify a value of the heat flux due to heat conductivity

$$
\psi(r, \theta, \varphi, t)=-\lambda_{\mathrm{e}}\left(\nabla T_{\mathrm{e}}\right)_{\|},
$$

where $\lambda_{\mathrm{e}}$ is the heat transfer coefficient for electrons; at the pole $\theta=0^{\circ}$, we use the averaging condition

$$
T_{\mathrm{e}}(r, t)=\lim _{\theta \rightarrow 0} \frac{1}{2 \pi} \int_{0}^{2 \pi} T_{\mathrm{e}}(r, \theta, \varphi, t) d \varphi
$$

at the equatorial boundary $\theta=50^{\circ}$, we use the results of solution of equation (2), which is onedimensional with respect to $r$; in longitude we set the periodicity condition

$$
T_{\mathrm{e}}(r, \theta, \varphi, t)=T_{\mathrm{e}}(r, \theta, \varphi+2 \pi, t) .
$$

The algorithm for solving the system of simulating equations as well as the boundary conditions for the rest of equations are described in [Golikov et al, 2012.; Gololobov et al., 2014]. For the numerical 
solution of three-dimensional differential equations (1)-(3), we utilize the method of total approximation [Samarsky 1977], in which the solution of three-dimensional differential equations reduces to the successive solution of a system of one-dimensional equations. Next, for one-dimensional equations, we use finite-difference approximation followed by reduction to the three-point scheme, which is solved by the tridiagonal matrix algorithm.

As the initial condition for $n\left(\mathrm{O}^{+}\right)$we use the simple Chapman layer and set electron and ion temperatures equal to the neutral gas temperature $\left(T_{\mathrm{e}}=T_{\mathrm{i}}=T_{\mathrm{n}}\right)$. The calculations involve the following steps: $\Delta r=$ $10 \mathrm{~km}, \Delta \theta=2^{\circ}, \Delta \varphi=10^{\circ}, \Delta t=2 \mathrm{~min}$. On a $\mathrm{PC}$ with a $2400 \mathrm{MHz}$ processor and $4000 \mathrm{Mb}$ random-access memory, it takes approximately 30 minutes to obtain a periodic solution.

\section{RESULTS OF NUMERICAL CALCULATIONS}

To find reasons for the occurrence of features in the spatial electron temperature distribution, first we analyze the main processes that cause variations of $T_{\mathrm{e}}$ in the $\mathrm{F} 2$ region under preset heliogeophysical conditions. Given that areas with elevated $T_{\mathrm{e}}$ can also be formed regardless of nonlocal heating [Mingalev, Mingaleva, 1992], the calculations are made assuming that there are no heat fluxes from the plasmasphere.

Figure 1 illustrates the distribution of the rate of oxygen atom ionization by ultraviolet solar radiation (photoionization) $(a, b)$ and the electron density $n_{\mathrm{e}}(c, d)$ at a height of $300 \mathrm{~km}$ at 05 and 17 UT for the conditions of winter solstice, minimum solar activity $\left(F_{10.7}=70\right)$, and moderate geomagnetic activity $\left(K_{\mathrm{p}}\right.$ =3) in LT coordinates (longitude) - geographic latitude. Here, electron (ion) densities are plotted as isolines. Concentric circles are geographic latitudes with a $10^{\circ}$ step. Numbers near the outer circle designate the local time; in brackets, the geographic longitude. Dashed lines indicate the position of terminator at a zenith angle $\chi=90^{\circ}$ (upper) and at a given height (lower). The point with two perpendicular lines marks the geomagnetic pole. Arrows denote electron velocities caused by the electric field of magnetospheric origin. The dash-dot circle indicates the plasmapause position, which corresponds to the equatorial boundary of the magnetospheric convection region according to Heppner's model " $\mathrm{A}$ ” [Heppner, 1977]. At $05 \mathrm{UT}$, the geomagnetic pole is near the midnight meridian; and at $17 \mathrm{UT}$, near the midday one. It is seen that at $300 \mathrm{~km}$, the terminator and the photoionization boundary move to high latitudes by $\sim 13^{\circ}$ (Figure 1, $a, b$ ). The electron density at $05 \mathrm{UT}$ in the zone between the two positions of the terminator falls rapidly, reaching night values in the lower position of the terminator in the near-noon sector (Figure 1, c). At $17 \mathrm{UT}$, since almost half of the convection region is on the illuminated side, the electron distribution becomes complicated. Over the polar cap, the tongue of ionization is formed because the daytime ionization is brought by antisolar convection to the nighttime side. On the side of low latitudes, the tongue is surrounded by trench-like ionospheric troughs in the dawn and dusk sectors. The troughs driven by the transport of weak nighttime ionization by convection to the daytime side extend until almost midday (Figure 1,d). At $17 \mathrm{UT}$, the initiation of corpuscular ionization leads to an increase in $n_{\mathrm{e}}$ in the convection zone, but the trench-like ionospheric trough in zones of dayside-directed convection remain unchanged in the dawn and dusk sectors (Figure 1,e,f). 
Figure 2 shows the distribution of rate of electron heating and cooling at $300 \mathrm{~km}$. It is evident that at this height, the boundary of electron gas heating and the terminator position roughly coincide (Figure 2, $a$, $b)$. The cooling rate $\left(\sum L_{\mathrm{e}}=L_{\mathrm{ei}}+L_{\mathrm{en}}\right)$ in the dawn sector is weaker than in the dusk one because the electron density in the morning is lower than in the evening (Figure 1) in the area between the two positions of the terminator (Figure 2,c). At 17 UT, the convection zone falls on the daytime side (almost half of the zone), and in the ionospheric troughs (trenches), which develop on the illuminated side due to the transport of weak nighttime ionization (Figure 1,d), the cooling rate drops as in Expression (6). In Figure $2, d$, this is clearly seen as two dark "crests" directed form the dawn and dusk sectors to the midday meridian. Note that at the height of the F2 region $L_{\mathrm{ei}}>L_{\mathrm{en}}$, as in [Perkins et al., 1978].
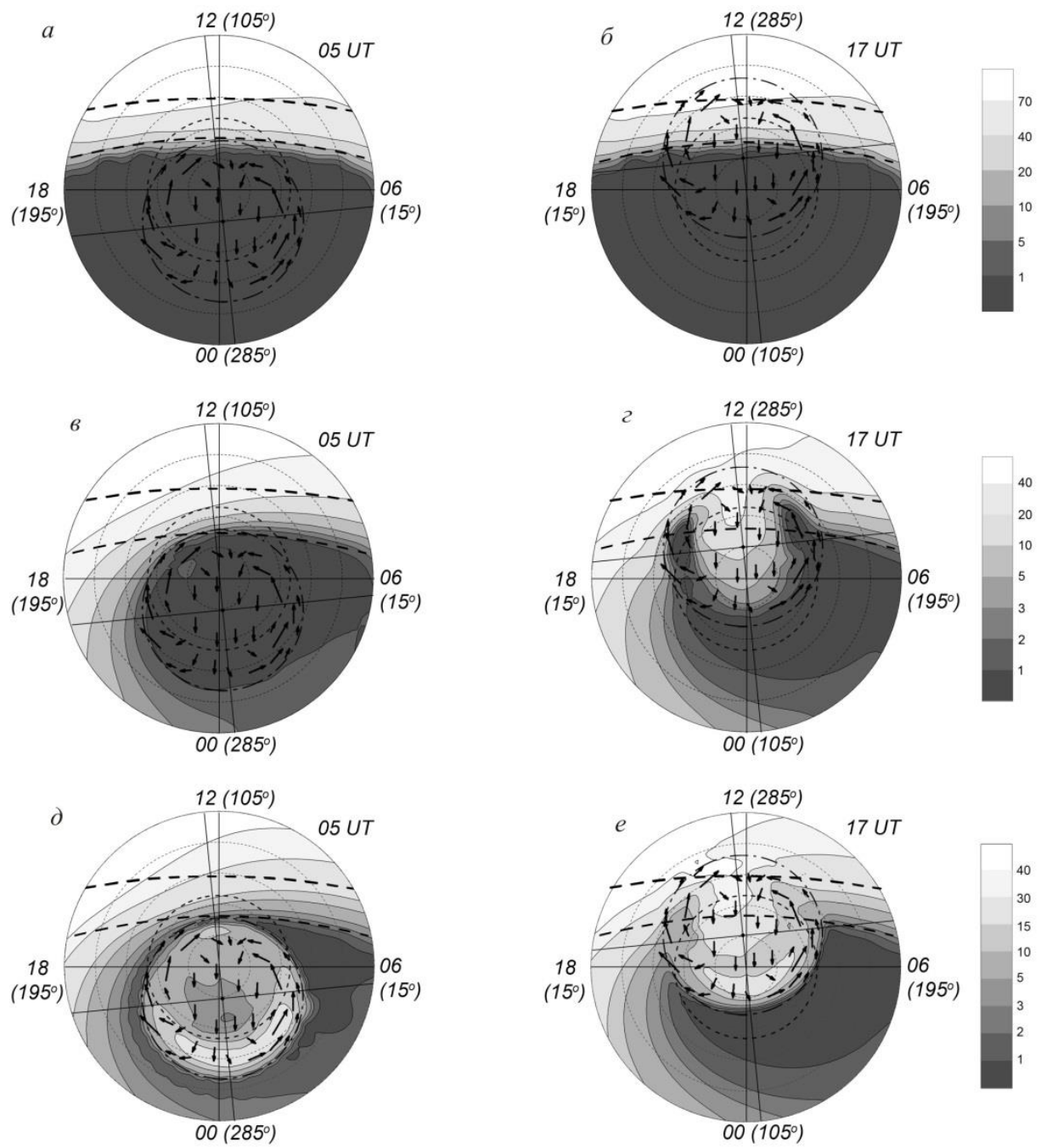

Figure 1. Distribution of ionization rate $(a, b)\left(\mathrm{cm}^{-3} \cdot \mathrm{s}^{-1}\right)$ and electron density $(c-f)\left(10^{4} \mathrm{~cm}^{-3}\right)$ at 05 and 17 UT at $300 \mathrm{~km}$ regardless of $(a-d)$ and with regard to $(e, f)$ charged particle precipitation events 

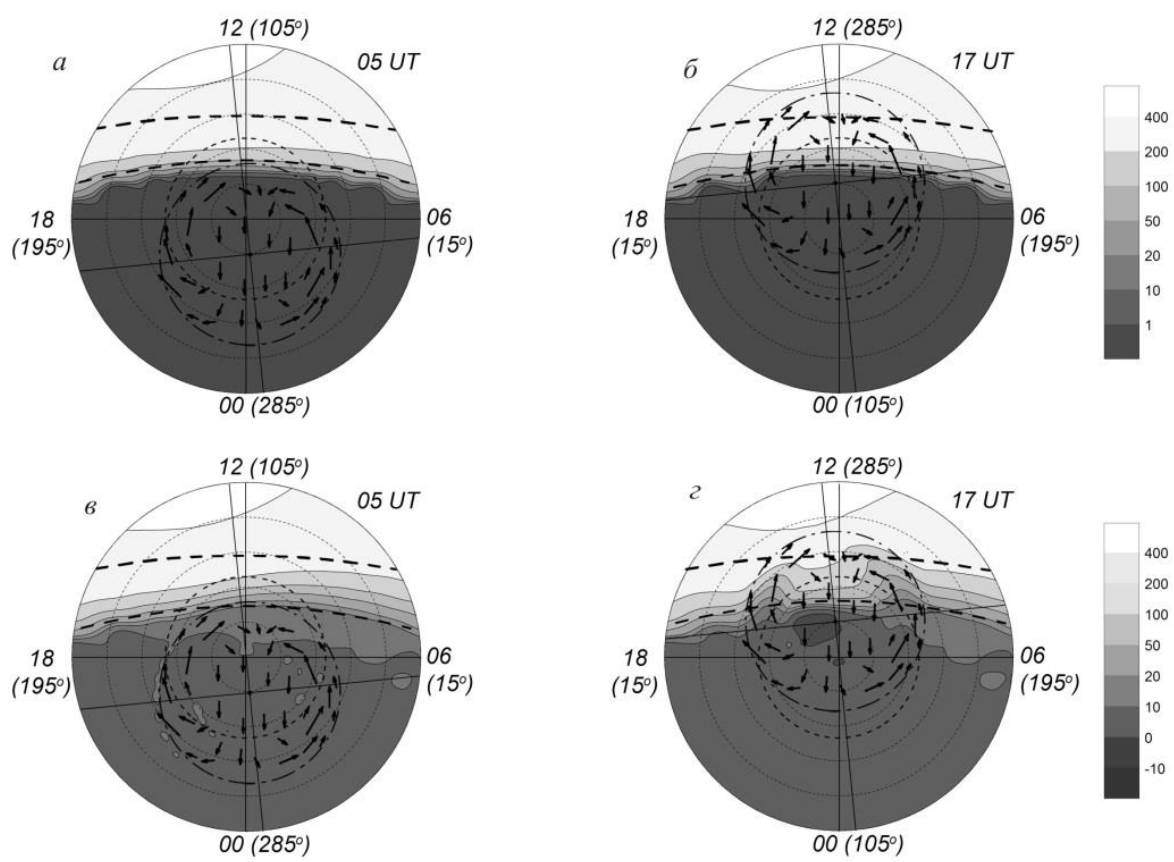

Figure 2. Distribution of the rate of electron heating by photoelectrons $(a, b)$ and the electron cooling rate $(c, d)$ $\left(\mathrm{eV} \cdot \mathrm{cm}^{-3} \cdot \mathrm{s}^{-1}\right)$ at $300 \mathrm{~km}$ at 05 and $17 \mathrm{UT}$
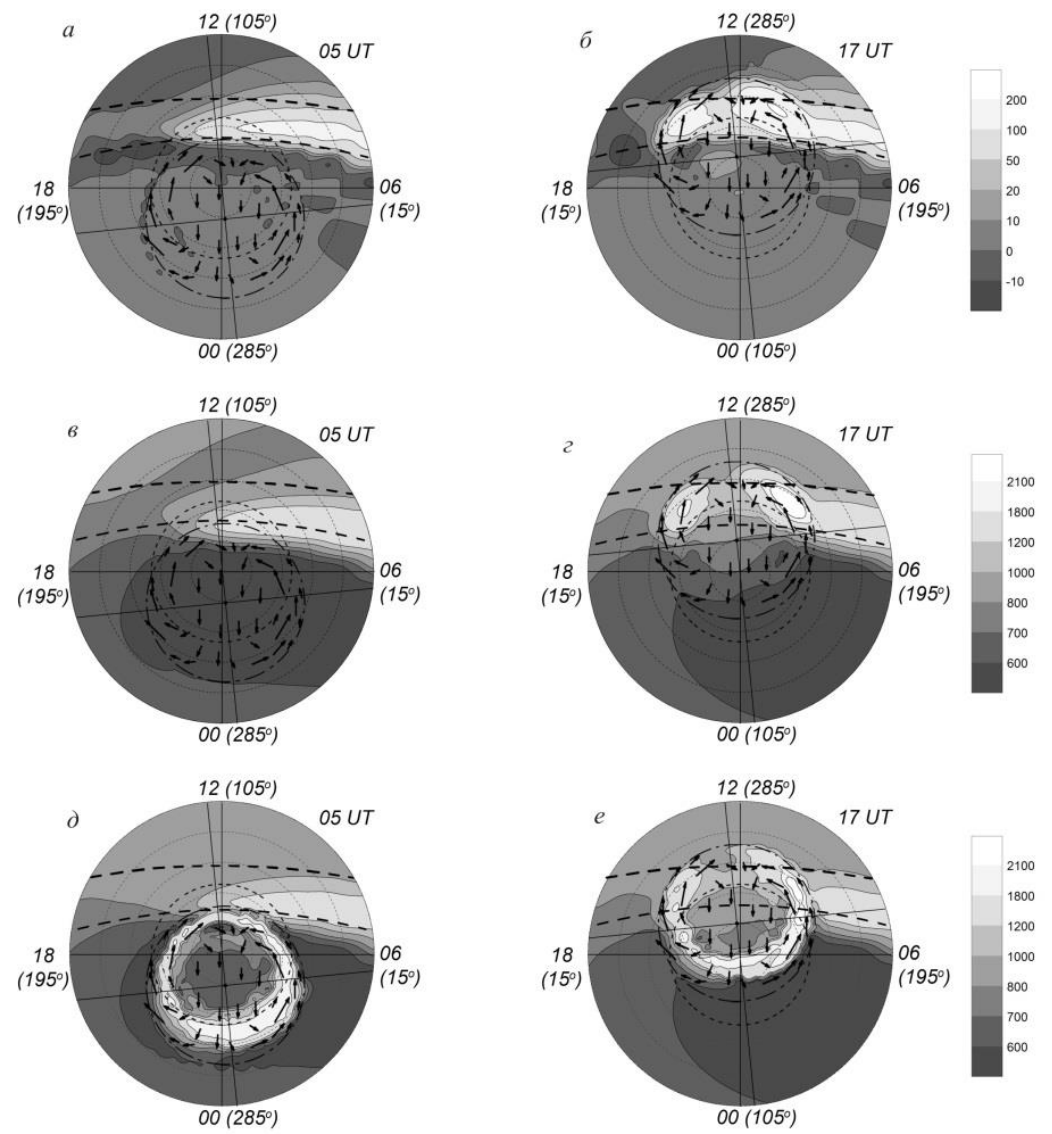

Figure 3. Distribution of the difference between the electron gas heating and cooling rates $(a, b)\left(\mathrm{eV}^{\mathrm{c}} \mathrm{cm}^{-3} \cdot \mathrm{s}^{-1}\right)$ and the electron temperature $(\mathrm{K})$ at 05 and $17 \mathrm{UT}$ at $300 \mathrm{~km}$, regardless of precipitations $(c, d)$ and with regard to them $(e, f)$ 

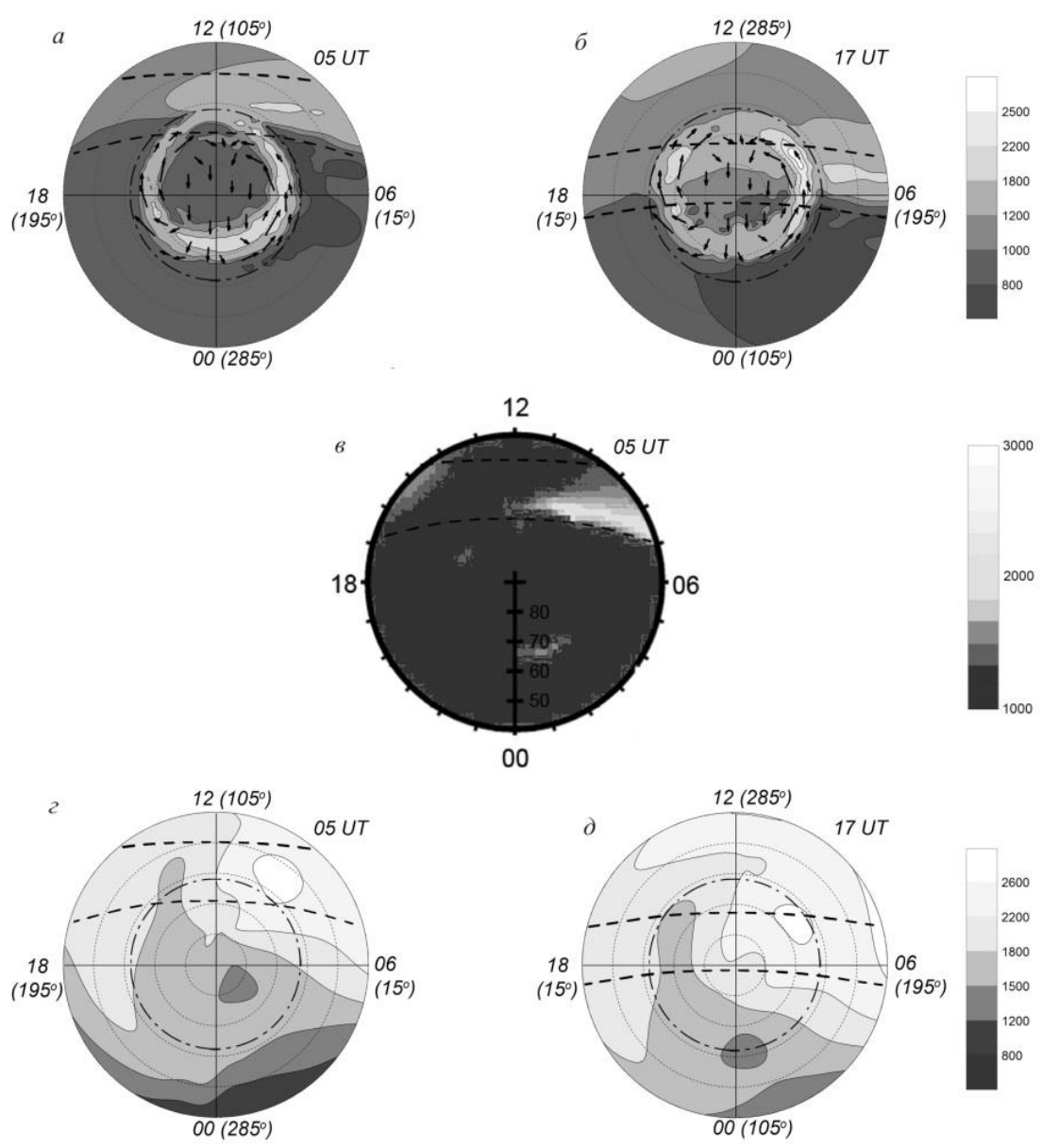

Figure 4. Electron temperature distribution as deduced from the calculation results obtained by the model of the high-latitude ionosphere $(a, b)$ at $400 \mathrm{~km}$, TDIM [David et al., 2011] at 400 and $800 \mathrm{~km}(c)$, and IRI$2012(d, e)(\mathrm{K})$ at $400 \mathrm{~km}$ for 05 and $17 \mathrm{UT}$ in geomagnetic coordinates

Figure 3, $a, b$ illustrates the calculated distribution of the difference between electron gas heating and cooling rates (or generalized rate) $\Delta_{\mathrm{e}}=Q_{\mathrm{e} \lambda}-\Sigma L_{\mathrm{e}}$ and electron temperature at $300 \mathrm{~km}$ at 05 and $17 \mathrm{UT}$. As anticipated, at 05 UT the heating rate prevails over the cooling rate in the dawn sector, where $\Delta_{\mathrm{e}}$ reaches values of $200 \mathrm{eV} \cdot \mathrm{cm}^{-3} \cdot \mathrm{s}^{-1}$ and more. At UT 17, the same values of $\Delta_{\mathrm{e}}$ are observed both in the dawn and dusk sectors in troughs with low electron density. Figure 3, $c, d$ shows that in the dawn sector in the area between the two positions of the terminator, where $\Delta_{\mathrm{e}}$ grows, a zone of elevated $T_{\mathrm{e}}$ develops. At UT 17, in regions of trench-like troughs (Figure 1, $d$ ) and in the zone between the positions of the terminator with increased $\Delta_{\mathrm{e}}$, electron temperature also rises, exceeding $2000 \mathrm{~K}$ in "epicenters" of the zone. Precipitation events cause $T_{\mathrm{e}}$ to elevate on the nighttime side (Figure 3, $e, f$ ).

Figure 4 shows the results obtained with the model of the high-latitude ionosphere $(a, b)$, the numerical model TDIM [David et al., 2011] (c), and the empirical model IRI-2012 [Bilitza, 2014, Truhlik et al., 2012] $(d, e)$ at 05 and 17 UT. The calculations were made for winter conditions, average solar activity $\left(F_{10.7}=160\right)$ and low geomagnetic activity $\left(K_{\mathrm{p}}=2\right)$ in the absence of heat fluxes from the plasmasphere. The terminator at a height of $400 \mathrm{~km}$ shifts northward of its first position by $\sim 18^{\circ}$. Figure $4, d, e$ depicts 
both the terminator positions as in Figure 4, $a, b$. It is seen that in TDIM at 05 UT at $400 \mathrm{~km}$ in the dawn sector between the two positions of the terminator, as in Figure 4, $a$, a zone of elevated $T_{\mathrm{e}}$ is formed. According to IRI-2012 data, at 05 UT the epicenter of the elevated $T_{\mathrm{e}}$ zone in the dawn sector is located between the terminator positions outside the convection zone as in Figure $4 a$, and at 17 UT inside it, as in Figure $4, b$. This is consistent with the results of calculations by the model of the high-latitude ionosphere. In [Xiong et al., 2013, Truhlik et al., 2012], the IRI model is shown to poorly describe the distribution of $n_{\mathrm{e}}$ and $T_{\mathrm{e}}$ in the sub-auroral and high-latitude ionosphere of the Northern Hemisphere. This is probably responsible for the absence of the zone with elevated $T_{\mathrm{e}}$ in the dusk sector at $17 \mathrm{UT}$. The qualitative agreement between the calculation results obtained with the three models allows us to state that the main causes for spatial and temporal distribution of electron temperature, which we discussed in this paper, are valid.

\section{CONCLUSION}

We have studied the spatial-temporal distribution of electron temperature in the F2 region of the high-latitude ionosphere, using numerical simulation and the three-dimensional model of the ionosphere, built on the basis of the Euler approach.

It has been shown that in the F2 region of the high-latitude ionosphere during minimum solar activity in winter solstice conditions, the mismatch between the poles leads to regular longitudinal features in the distribution of $T_{\mathrm{e}}$ during Earth's daily rotation: at 05 UT, when the Eastern Hemisphere is on the daytime side, a zone of elevated $T_{\mathrm{e}}$ is formed only in the dawn sector; at $17 \mathrm{UT}$, when the Western Hemisphere is illuminated, in both the sectors. In this case, the mechanism of formation of these zones with elevated $T_{\mathrm{e}}$ is as follows: in the absence of a heat flux downflow in the dayside ionosphere in regions of electron density troughs, where the electron gas cooling rate is lower than that outside them, $T_{\mathrm{e}}$ increases. This is consistent with [Schunk et al., 1986]. Further, we have demonstrated that causes of the formation of electron density troughs at different longitudes differ. So, at 05 UT, a trough near the terminator in the Eastern Hemisphere develops from the rapid attenuation of solar ionizing radiation at $\mathrm{x}>90^{\circ}$ when the convection zone related to the geomagnetic pole is on the nighttime side. At UT 17, when this zone is partially illuminated in the Western Hemisphere, troughs are formed in the dawn and dusk sectors due to the transport of the weak nighttime ionization to the daytime side by convection, therefore at this moment of universal time we can expect formation of two zones of elevated $T_{\mathrm{e}}$.

Finally, let us note that the numerical model of the high-latitude ionosphere described in this paper can be used to study its thermal regime, in particular, to examine causes of the formation of hot spots observable at heights of the $\mathrm{F} 2$ region.

This work was supported by RFBR grant No. 15-45-05090-r_vostok_a and 15-45-05066-r_vostok_a. 


\section{REFERENCES}

Banks P.N., Kockarts G. Aeronomy. Part A, B. New York: Academic Press, 1973. 785 p.

Bilitza D. Altadill D., Zhang Y., C. Mertens, V. Truhlik, P. Richards, L.-A. McKinnell, B. Reinisch. The International Reference Ionosphere 2012 - a model of international collaboration. J. Space Weather Space Clim., 2014, vol. A07, pp. 1. DOI: 10.1051 / swsc / 2014004.

Chapman S. The absorption and dissociative of ionizing effect of monochromatic radiation in an atmosphere on a rotation Earth. Proc. Phys. Soc. 1931, vol. 43, no. 5, pp. 483-501. DOI: 10.1088/0959-5309/43/5/302.

David M., Schunk R.W., Sojka J.J. The effect of downward electron heat flow and electron cooling processes in the high-latitude ionosphere. J. Atm. Solar-Terr. Phys. 2011, vol. 73, no. 16, pp. 2399-2409. DOI: 10.1016 / j.jastp.2011.

Fang X., Randall C., Lummerzheim D., S.C. Solomon, M.J. Mills, D.R. Marsh, C.H. Jackman, Wenbin Wang, Gang Lu. Electron impact ionization: A new parameterization for $100 \mathrm{eV}$ to $1 \mathrm{MeV}$ electrons. J. Geophys. Res. 2008, vol. 113, pp. A09311. DOI: 10.1029 / 2008JA013384.

Golikov I.A., Gololobov A.Yu., Popov V.I. Numerical modeling of thermal conditions of the high-latitude ionosphere. Vestnik Severo-Vostochnogo federal'nogo universiteta [Bull. of the North-Eastern Federal University]. 2012, vol. 9, no. 3, pp. 22-28. (In Russian).

Gololobov A.Yu., Golikov I.A., Popov V.I. Modeling the high-latitude ionosphere adjusted for mismatch between geographic and geomagnetic poles Vestnik Severo-Vostochnogo federal'nogo universiteta [Bull. of the NorthEastern Federal University]. 2014, vol. 11, no. 2, pp. 46-54. (In Russian).

Heppner J.P. Empirical model of high electric field. J. Geophys. Res. 1977, vol. 82, no. 7, pp. 1115-1125. DOI: 10.1029 / JA082i007p01115.

Klimenko V.V., Koren'kov Yu.N., Namgaladze A.A., Karpov I.V., Surotkin V.A., Naumova N.M. Numerical modeling of "hot spots" in Earth's magnetosphere. Geomagnetizm i aeronomiya [Geomagnetism and Aeronomy]. 1991, vol. 31, no. 3, pp. 554-557. (In Russian).

Koffman W., Wickwar V.B. Very high electron temperature in the daytime F region at Sondrestrom. Geophys. Res. Lett. 1984, vol. 1, no. 9, pp. 912-922. DOI: 10.1029 / GL011i009p00919.

Kolesnik A.G., Golikov I.A. Mechanism of formation of the main ionospheric trough in F region. Geomagnetizm i aeronomiya [Geomagnetism and Aeronomy]. 1983, vol. 23, no. 4, pp. 909-914. (In Russian).

Kolesnik A.G., Golikov I.A., Chernyshev V.I. Mathematical Models of the Ionosphere. Tomsk: Rasko Publ., 1993. 240 p. (In Russian).

Krinberg I.A., Tashhilin A.V. Ionosphere and Plasmasphere. Moscow: Nauka Publ., 1984. 189 p. (In Russian).

Mingalev G.I., Mingaleva V.S. Effect of electron temperature increase in the main ionospheric trough due to internal processes in different seasons Geomagnetizm i aeronomiya [Geomagnetism and Aeronomy]. 1992, vol. 31, no. 2, pp. 83-87.

Mingalev G.I., Mingaleva V.S. Simulation of the spatial structure of the high-latitude F-region for different conditions of solar illumination of the ionosphere. Proc. XXV Annual Seminar "Physics of Auroral Phenomena". Apatity, 2002, pp. 107-110.

Perkins F.W., Roble R.G. Ionospheric heating by radio waves: prediction for Arecibo and the satellite power station. J. Geophys. Res. 1978, vol. 83, no. 4, pp. 1611-1624.

Picone J.M., Hedin A.E., Drob D.P., Aikin A.C. NRLMSISE-00 empirical model of the atmosphere: Statistical comparison and scientific issues. J. Geophys. Res. 2002, vol. 107, no. A12, pp. 1501-1516.

Samarsky A.A. The theory of difference schemes. Moscow: Nauka Publ., 1977. 656 p. (In Russian).

Schunk R.W., Nagy A.F. Electron temperature in the F-regions of the ionosphere: theory and observations. Rev. Geophys. Space Phys. 1978, vol. 16, no. 3, pp. 355-399.

Schunk R.W., Sojka J.J., Bowline M.D. Theoretical study of the electron temperature in the high-latitude 
Modeling the electron temperature distribution...

ionosphere for solar maximum and winter conditions. J. Geophys. Res. 1986, vol. 91, no. A11, pp. 12041-12054.

Stubbe P. Simultaneous solution of the time dependent coupled continuity equations, heat conduction equations, and equations of motion for a system consisting of a neutral gas, an electron gas, and a four component ion gas. $J$. Atmos. Terr. Phys. 1970, vol. 32, no. 9, pp. 865-903.

Truhlik V., Bilitza D., Triskova L. A new global empirical model of the electron temperature with the inclusion of the solar activity variations for IRI. Earth, Planets and Space. 2012, vol. 64, pp. 531-543.

Vorobjev V.G., Yagodkina O.I., Katkalov Yu.V. Auroral precipitation model and its applications to ionospheric and magnetospheric studies. J. Atmos. Solar-Terr. Phys. 2013, vol. 102, pp. 157-171.

Xiong C., Luhr H., Ma S.Y. The subauroral electron density trough: Comparison between satellite observations and IRI-2007 model estimates. Adv. Space Res. 2013, vol. 51, pp. 536-544. 